\title{
Minimally invasive and robotic approaches to mitral valve surgery: Transthoracic aortic crossclamping is optimal
}

\author{
Michael J. Bates, MD, FACS, and W. Randolph Chitwood, Jr, MD, FACS, FRCS (England)
}

"The value of an idea lies in the using of it."

-Thomas Edison

Throughout the history of cardiac surgery, external clamping of the ascending aorta has been essential to the conduct of both intracardiac and epicardial operations. Endothelial, hemodynamic, and humoral effects of external aortic clamping and unclamping have been studied extensively. ${ }^{1-3}$ As transmural forces on the internal aorta are more than 8 times the systemic blood pressure when applied, clamp design and application are important to distribute these forces to minimize endothelial injury. Dr Michael DeBakey designed perhaps the best clamp jaws to distribute these forces, and they still provide adequate tissue grip stability. While some cardiac procedures can be performed safely without aortic occlusion, either employing circulatory arrest, ventricular fibrillation, or beating-heart methods, these techniques generally are not applicable to the majority of cardiac operations.

In the mid-1990s, Cohn and colleagues ${ }^{4}$ and Cosgrove and colleagues, ${ }^{5}$ among others, began to perform the first minimally invasive aortic and mitral valve operations through either an upper hemi-sternotomy or parasternal incision using traditional aortic crossclamps. During this period, it was our vision that the best approach for minimally invasive mitral valve surgery would be through a minithoracotomy using hypothermic cardioplegia. Previous right thoracotomy mitral reoperations had shown us that this approach provides excellent visualization and instrument access. ${ }^{6}$

In 1996, a group of innovative surgeons from Stanford developed and applied the catheter-based Heartport endoballoon occlusion device (Edwards Lifesciences Inc, Irvine, Calif) to replace mitral valves and perform coronary surgery through a tiny "working port" or "port-access.",-9 In the United States, a clinical trial using the endoballoon

\footnotetext{
From the Department of Cardiovascular Sciences, East Carolina Heart Institute, East Carolina University and Vidant Medical Center, Greenville, NC.

Received for publication Sept 14, 2021; accepted for publication Sept 16, 2021; available ahead of print Sept 22, 2021

Address for reprints: W. Randolph Chitwood, Jr, MD, FACS, FRCS (England), 146 East Longmeadow Rd, Greenville, NC 27858 (E-mail: chitwoodw@ecu.edu) JTCVS Techniques 2021;10:84-8

2666-2507

Copyright (C) 2021 The Author(s). Published by Elsevier Inc. on behalf of The American Association for Thoracic Surgery. This is an open access article under the CC BY-NC-ND license (http://creativecommons.org/licenses/by-nc-nd/4.0/). https://doi.org/10.1016/j.xjtc.2021.09.034
}

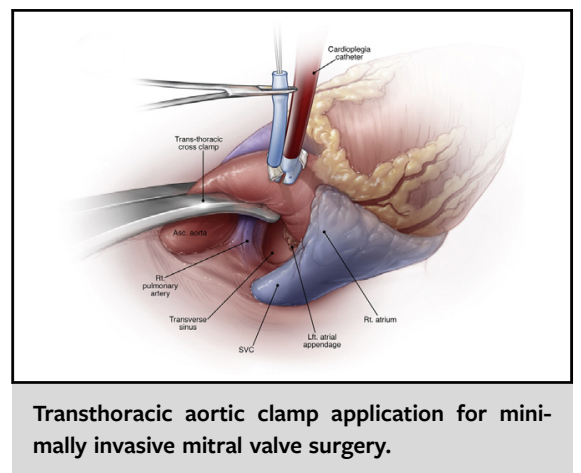

\begin{abstract}
CENTRAL MESSAGE
Compared with the complexities and cost of using the endoballoon, the transthoracic clamp is easy to teach, simple to apply, remains stable in position, is reusable, and has an economic benefit.
\end{abstract}

See Commentaries on pages 89 and 90.

was begun at Stanford and New York Universities, and access to this device was limited to their trial. At that time, we considered that endoballoon occlusion method was complex and not proven to be safe or effective, and there was a considerable expense added to each procedure.

We then reflected on Dr DeBakey's genius, and it became obvious that a thin long clamp would be ideal for minimally invasive mitral surgery to achieve optimal and stable aortic occlusion. We consulted the Scanlan International, Inc, group of instrument engineers, and they took this idea to develop a long sliding-rod clamp with DeBakey-type jaws (Figure 1). This became the Chitwood-DeBakey Transthoracic Clamp, which has been a mainstay in our minimally invasive approach to mitral valve repairs and replacements since $1996 .{ }^{10-14}$ We have used this specific clamp in nearly 3000 videoscopic and robot-assisted operations done at our institution or during training at other centers (Figure 4). Several flexible-arm aortic clamps also are manufactured and are very effective for use in minimally invasive mitral operations (eg, the Cygnet-Flexible and Cosgrove-Flex clamps). No matter which clamp is selected, we believe that transthoracic aortic clamping is 


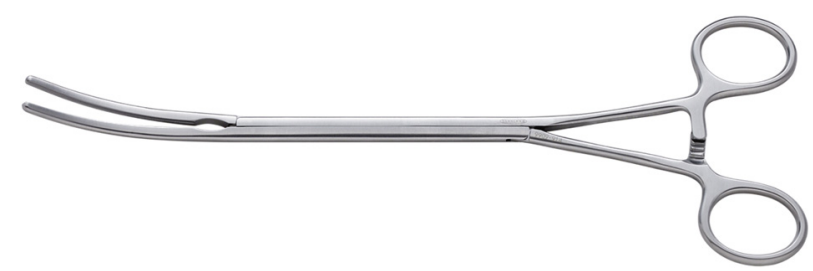

FIGURE 1. Transthoracic aortic clamp: The posterior "arm" of the clamp is immobile and should be passed posterior to the aorta in the transverse sinus. During application, the sliding rod shaft mechanism activates the anterior "arm." Courtesy of Scanlan International, Inc.

optimal for performing either direct vision or videoscopic minimally invasive as well as robot-assisted mitral valve surgery.

\section{ENDOBALLOON AORTIC OCCLUSION}

The evolving use of aortic endoballoon occlusion for direct vision, videoscopic, and robot-assisted minimally invasive mitral valve surgery has subtended 2 distinct eras. There was the early investigation and adoption period and a later one that incorporated an improved device and a more refined approach. Most importantly, these 2 eras can be compared by their distinct differences in clinical results. The early experience with port-access "Heartport" mitral valve surgery was not encouraging. One initial report described an operative mortality of $9.8 \%$, with a stroke rate of $7.8 \%$. Moreover, $3.9 \%$ of patients had an intraoperative aortic dissection. ${ }^{15}$ At the same meeting, we reported our first 31 videoscopic minimally invasive mitral operations using the newly developed transthoracic clamp with no strokes or aortic major complications. ${ }^{11}$ Despite these early concerns, over time, increased experience and improvements in the device have made endoballoon use comparable in both safety and outcomes with the transthoracic clamp.

There are several major advantages of using the endoballoon versus transthoracic clamping during minimally invasive mitral valve operations. With the endoballoon, the size and number of incisions can be reduced. There is less chance of intercostal bleeding, as no incision is needed as with insertion of the transthoracic clamp. Also, there is a central catheter lumen for cardioplegia delivery, obviating the need to place an aortic root cannula and reducing intrathoracic clutter, which is paramount for totally endoscopic procedures. In reoperative mitral surgery, the endoballoon does not require dissection to expose the ascending aorta, which is necessary for external aortic clamping.

With advances in endoballoon technology and intraoperative techniques, a number of reports have shown comparable safety and outcomes when applied during with videoscopic and robot-assisted operations. ${ }^{16,17}$ As an example, in 2014 Ward and colleagues ${ }^{18}$ reported that in
105 of 108 patients $(97.2 \%)$, endoballoon aortic occlusion was used during totally endoscopic minimally invasive mitral repairs. There were no hospital mortalities, aortic injuries, vascular complications, or wound infections, with 2 strokes reported as the only complications. ${ }^{18}$ Recently, this group also showed that by adding albumen bound fluorescein dye to the saline used for balloon expansion, surgeons now can monitor continuously intra-aortic position to prevent device migration. ${ }^{19}$ This has eased the burden of continuous echo monitoring.

\section{TRANSTHORACIC AORTIC CrossClamping}

For direct vision, videoscopic, or robot-assisted mitral operations, the clamp should be inserted through the right second or third intercostal space (Figure 2). For robot-assisted operations, it is important to place the clamp in the mid-to posterior axillary line to avoid conflicts with the left instrument arm. Thereafter, it should be passed closely in front of the superior vena cava at pericardial junction. With left atrial retractor elevation, caval impingement by the clamp can impair venous return to the pump, and we avoid this risk by placing a right internal jugular venous drainage cannula. To avert injury during clamp transverse sinus passage, it is paramount to the visualize the right pulmonary artery and left atrial appendage before deployment (Figures 3 and 4). At the same time, care must be taken to avoid crowding the ascending aorta cardioplegia catheter.

A major advantage of the clamp is that application is easy and reproducible. As mentioned, endoballoon migration is possible, causing innominate artery obstruction. The clamp technique offers stable aortic occlusion with no potential for intraoperative migration, obviating the need for constant monitoring. In addition, because of stable aortic occlusion, bilateral radial artery pressure monitoring is not necessary. Lastly, in patients with small femoral arteries, introduction of the endoballoon through the central lumen of perfusion cannula can prevent adequate arterial inflow. In this circumstance, the contralateral femoral artery must be used to introduce the endoballoon. This is not a problem when using the clamp.

\section{TRANSTHORACIC AORTIC CLAMP VERSUS ENDOBALLOON OCCLUSION: WHICH IS BETTER?}

The goal for any mitral valve operation is to achieve a successful repair or replacement with minimal morbidity and mortality. Using either external aortic clamping or endoluminal occlusion, minimally invasive mitral valve surgery has been established as a safe and durable approach at experienced centers. More patients are being operated using minimally invasive methods. Recent American College of Cardiology/American Heart Association guidelines have expanded indications for mitral valve 


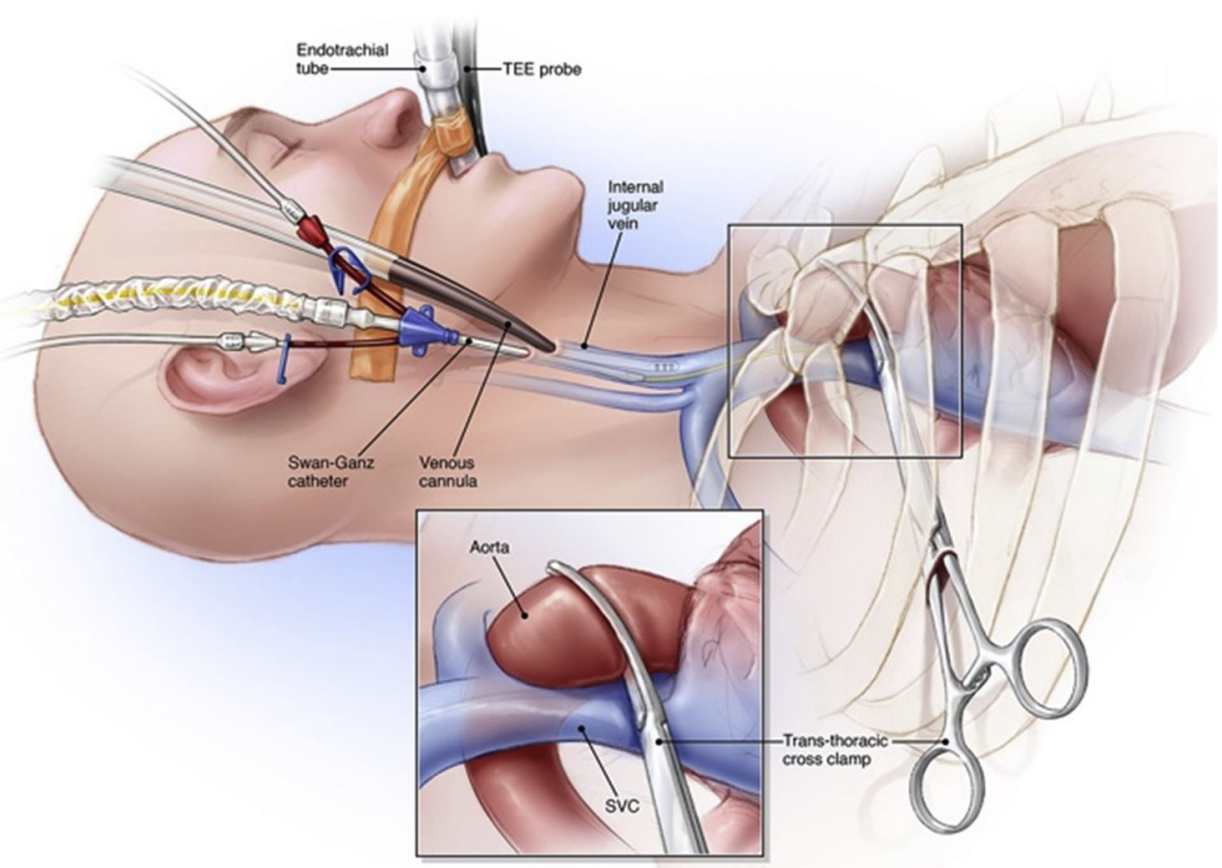

FIGURE 2. Transthoracic aortic clamp application: The transthoracic aortic clamp is passed through the second or third intercostal space in the mid to posterior axillary line just in front of the superior vena cava $(S V C)$ and then advanced in a trajectory toward the transverse sinus. A jugular venous cannula is placed for venous drainage to compensate for any caval obstruction with left atrial retraction. TEE, Transesophageal echo probe. C2021 Society of Thoracic Surgeons. All rights reserved. With permission of the Society of Thoracic Surgeons.

repairs in patients with asymptomatic severe mitral regurgitation and have preserved left ventricular function. This is if they have surgery at a center where there is a $>95 \%$ chance of a repair with an expected operative mortality of $<1 \%$. $^{20}$

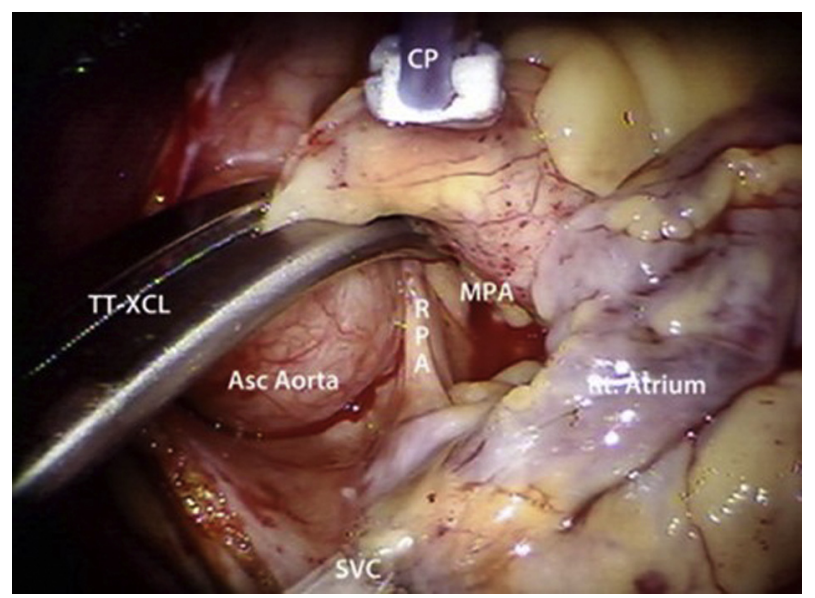

FIGURE 3. Transverse sinus anatomy. The deployed transthoracic clamp $(T T-X C L)$ has been passed into the transverse sinus while visualizing both the right $(R P A)$ and main pulmonary arteries $(M P A)$ as well as the left atrial appendage. In this photograph, the clamp has been rotated counterclockwise away from the superior vena cava $(S V C)$ to demonstrate the transverse sinus anatomy. CP, Cardioplegia catheter; Asc Aorta, ascending aorta; Rt. Atrium, right atrium. Photograph by the author, W.R.C.
As mentioned, the development of the transthoracic clamp paralleled closely the emergence of the endoballoon occlusion device. In the early years, there was great skepticism regarding safety and long-term outcomes of any type of minimally invasive mitral valve surgery. However, over the past 2 decades, these operations have been proven to be safe and with comparable outcomes to sternotomy-based operations. Multiple individual center reports and meta-analyses have shown that both transthoracic clamp and endoballoon aortic occlusion have similar safety records with a low incidence of major morbidity and mortality. ${ }^{21-25}$ In addition, there appears to be only minor differences in operative clamp and bypass times between these devices. According to the Society of Thoracic Surgeons (STS) Research Center, approximately $70 \%$ of minimally invasive mitral operations in the United States, whether robot-assisted or otherwise, are currently being done with the transthoracic crossclamp and $28 \%$ with the endoballoon (STS Research Center). Thus, the preponderance of evidence suggests that both approaches are equivalent in terms of complications, including strokes and mortality. Nevertheless, some reports have shown a slight tendency to have more retrograde dissections with the endoballoon technique. ${ }^{13,22}$ The Cleveland Clinic group ${ }^{26}$ and Murphy and colleagues, ${ }^{17}$ among others, have shown definitively that preoperative computed tomography scanning is important to reduce of 


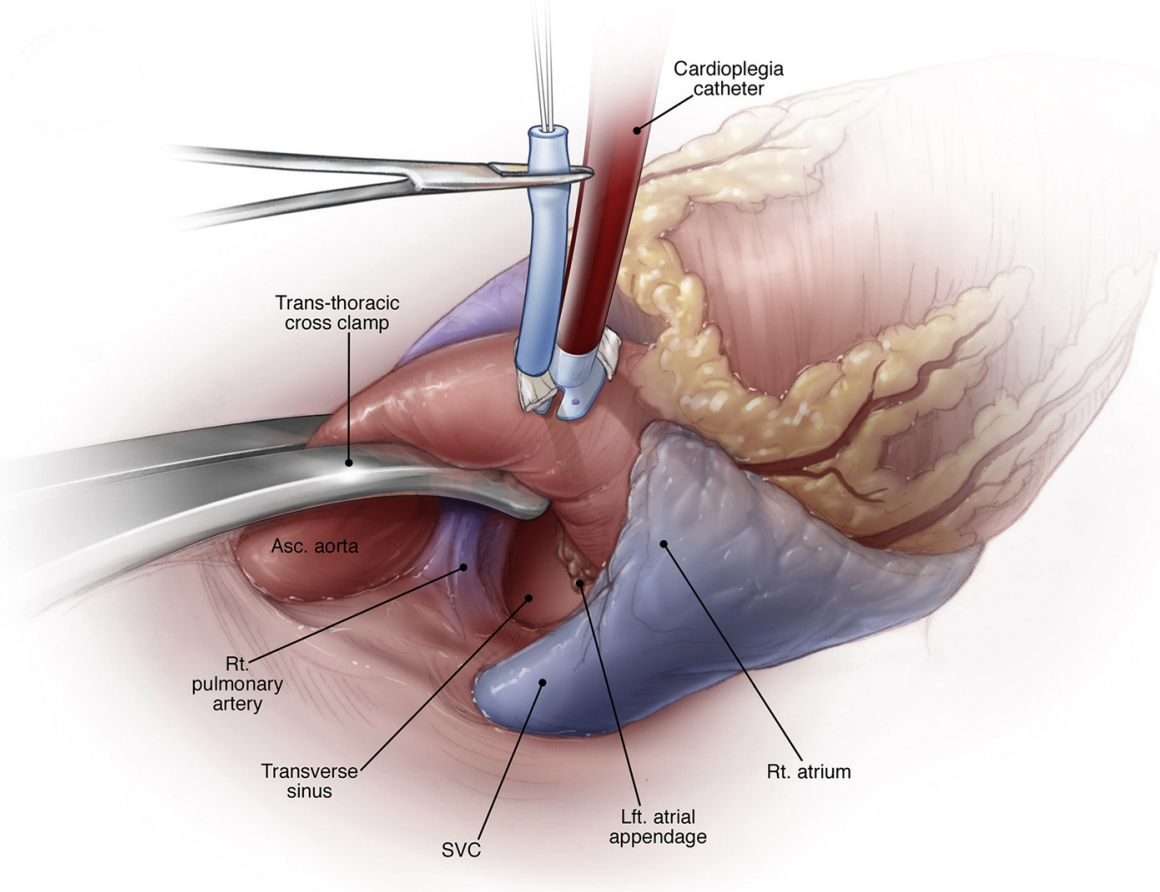

FIGURE 4. In this illustration, the transthoracic crossclamp has been deployed through the transverse sinus to occlude the ascending aorta (Asc. Aorta). To avoid injury to either the right (Rt.) pulmonary artery or left ( $L f t$.) atrial appendage, both must be visualized before inserting the clamp. Moreover, enough room should be left between the clamp and the cardioplegia catheter to avoid compromising cardioplegia administration. In this view, the aorta has been rotated ventrally away from the superior vena cava $(S V C)$ to demonstrate the contents of the transverse sinus. In actuality, the clamp arm trajectory should pass just in front of the SVC, near the junction with the right atrium (Rt. atrium). (C2021 Society of Thoracic Surgeons. All rights reserved. With permission of the Society of Thoracic Surgeons.

strokes and possibly aortic dissections using either technique.

We believe that the transthoracic clamp offers many advantages over endoballoon aortic occlusion. External aortic clamping has been historically inherent in nearly all cardiac operations. Transthoracic clamp deployment is easily taught and adopted without a steep learning curve. When surgeons are beginning videoscopic or robot-assisted mitral valve surgery, it seems prudent to use the clamp. It is very difficult learn and apply 2 separate technology platforms at the same time. Economic considerations are important today. The price of each transthoracic crossclamp is $\$ 2000$ and can be reused multiple times over many years compared with the endoballoon, costing an average of $\$ 5000.00$ per operation. To put this in perspective, endoballoon costs for 100 operations would be $\$ 500,000.00$.

Taking all the available evidence into consideration, the transthoracic clamp and endoballoon offer similar safety profiles in terms of major complications. There are advantages and disadvantages to each technique; however, we believe that the simplicity and economy of the transthoracic clamp makes usage superior to the endoballoon in the current era of minimally invasive mitral valve surgery.

\section{Conflict of Interest Statement}

Dr Chitwood is the inventor of the transthoracic aortic crossclamp and receives minor royalties. Dr Bates reported no conflicts of interest.

The Journal policy requires editors and reviewers to disclose conflicts of interest and to decline handling or reviewing manuscripts for which they may have a conflict of interest. The editors and reviewers of this article have no conflicts of interest.

\section{References}

1. Bianchi G, Pucci A, Matteucci M, Varone E, Romano S, Lionetti V, et al. Mechanical properties and biological interaction of aortic clamps: are these all minimally invasive? Innovations. 2013;8:42-9.

2. Zammert M, Gelman S. The pathophysiology of aortic cross-clamping. Best Pract Res Clin Anaesth. 2016;30:257.e269.

3. Babin-Ebella J, Gimpel-Henning K, Sievers H, Scharfschwerdt M. Influence of clamp duration and pressure on endothelial damage in aortic cross-clamping. Interactive Cardiovasc Thorac Surg. 2010;10:168-71.

4. Cohn LII, Adams DII, Couper GS, Bichell DP, Rosborough DM, Sears SP, et al. Minimally invasive cardiac valve surgery improves patient satisfaction while reducing costs of cardiac valve replacement and repair. Ann Surg. 1997;226: 421-6.

5. Cosgrove DM, Sabik JF, Navia JL. Minimally invasive valve surgery. Ann Thorac Surg. 1998;65:1535-8.

6. Tribble CG, Killinger WA, Harman PK, Crosby IK, Nolan SP, Kron IL. Anterolateral thoracotomy as an alternate to repeat median sternotomy for replacement of the mitral valve. Ann Thorac Surg. 1987;43:380-2. 
7. Stevens JH, Burdon TA, Peters WS, Siegel LC, Pompili MF, Vierra MA, et al. Port-access coronary artery bypass grafting: a proposed surgical method. J Thorac Cardiovasc Surg. 1996;111:567-73.

8. Schwarz DS, Ribakove GH, Grossi EA, Stevens JH, Siegel LC, St Goar FG, et al Minimally invasive cardiopulmonary bypass with cardioplegic arrest: a closed chest technique with equivalent myocardial protection. J Thorac Cardiovasc Surg. 1996;111:557-65.

9. Pompili MF, Stevens JH, Burdon TA, Siegel LC, Peters WS, Ribakove GH, et al. Port-access mitral valve replacement in dogs. J Thorac Cardiovasc Surg. 1996; 112:1268-74.

10. Chitwood WR Jr, Elbeery JR, Moran JF. Minimally invasive mitral valve repair using transthoracic aortic occlusion. Ann Thorac Surg. 1997;63: 1477-9.

11. Chitwood WR Jr, Elbeery JR, Chapman WH, Moran JM, Lust RL, Wooden WA, et al. Video-assisted minimally invasive mitral valve surgery: the "micro-mitral" operation. J Thorac Cardiovasc Surg. 1997;113:413-4.

12. Chitwood WR Jr, Wixon CL, Elbeery JR, Moran JF, Chapman WH, Lust RM. Video-assisted minimally invasive mitral valve surgery. J Thorac Cardiovasc Surg. 1997;114:773-80.

13. Modi P, Rodriguez E, Hargrove WC III, Hassan A, Szeto WY, Chitwood WR Jr. Minimally invasive video-assisted mitral valve surgery: a 12-year, 2-center experience in 1178 patients. J Thorac Cardiovasc Surg. 2009;137:1481-7.

14. Nifong LW, Rodriguez E, Chitwood WR Jr. 540 consecutive robotic mitral valve repairs including concomitant atrial fibrillation cryoablation. Ann Thorac Surg. 2012;94:38-42.

15. Mohr FW, Falk V, Diegeler A, Walther T, van Son JA, Autschbach R. Minimally invasive port-access mitral valve surgery. J Thorac Cardiovasc Surg. 1998;115: 567-74.

16. Casselman F, Aramendi J, Ventala M, Candolfi P, Coppoolse R, Gersak B, et al. Endoaortic clamping does not increase the risk of stroke in minimal access mitral valve surgery: a multicenter experience. Ann Thorac Surg. 2015;100: 1334-9.

17. Murphy DA, Moss E, Binongo J, Miller JS, Macheers SK, Sarin EL, et al. The expanding role of endoscopic robotics in mitral valve surgery: 1,257 consecutive procedures. Ann Thorac Surg. 2015;100:1675-81.
18. Ward A, Loulmet DF, Neuberger PJ, Grossi EA. Outcomes of peripheral perfusion with balloon aortic clamping for totally endoscopic robotic mitral valve repair. J Thorac Cardiovasc Surg. 2014;148:2769-72.

19. Yaffee DW, Loulmet DF, Fakiha AG, Grossi EA. Fluorescence-guided placement of an endoballoon occlusion device for totally endoscopic robotic mitral valve repair. J Thorac Cardiovasc Surg. 2015;149:1456-8.

20. Nishimura RA, Otto CM, Bonow RO, Carabello BA, Erwin JP III, Guyton RA, et al. 2014 AHA/ACC guideline for the management of patients with valvular heart disease: a report of the American College of Cardiology/American Heart Association task force on practice guidelines. J Am Coll Cardiol. 2014;63: e57-185.

21. Reichenspurner H, Detter C, Deuse T, Bohm DH, Tredde H, Reichert B. Video and robotic assisted minimally invasive mitral valve surgery: a comparison of the port-access and transthoracic clamp techniques. Ann Thorac Surg. 2005;79: 485-90.

22. Khan H, Hadjittofi C, Uzzaman M, Salhiyyah K, 511 Garg S, Butt S, et al. External aortic clamping versus endoaortic balloon occlusion in minimally invasive cardiac surgery: a 513 systematic review and meta-analysis. Interact Cardiovasc Thorac Surg. 2018;27:208-14.

23. Barbero C, Krakor M, Bentala M, Casselman F, Candolfi P, Goldstein J, et al. Comparison of endoaortic and transthoracic aortic clamping in minimal invasive mitral valve surgery. Ann Thorac Surg. 2018;105:794-8.

24. Atluri P, Goldstone AB, Fox JY, Szeto WY, Hargrove WC. Port access cardiac operations can be safely performed with either endoaortic balloon or Chitwood clamp. Ann Thorac Surg. 2014;98:1579-84.

25. Loforte A, Luzi G, Montalto A, Ranocchi F, Polizzi V, Sbaraglia F, et al. Video-assisted minimally invasive mitral valve surgery external aortic clamp versus endoclamp techniques. Innovations (Phila). 2010;5:413.

26. Gillinov AM, Mihahaljevic T, Javadikasgari H, Suri RM, Mick SL, Navia JL, et al. Early results of robotically assisted mitral valve surgery: analysis of the first 1000 cases. J Thorac Cardiovasc Surg. 2018;155:82-91.

Key Words: transthoracic clamp, endoballoon, minimally invasive, mitral surgery 